Table 1. (Continued)

\begin{tabular}{ccc} 
& \multicolumn{2}{c}{ SARS-COV-2 Detected } \\
\cline { 2 - 3 } Mask No. & $\begin{array}{c}\text { Before } \\
\text { Decontamination }\end{array}$ & $\begin{array}{c}\text { After } \\
\text { Decontamination }\end{array}$ \\
\hline Mask 7 & & No \\
\hline Outside swab & No & No \\
\hline Inside swab & No & No \\
\hline Sample & No & No \\
\hline Mask 8 & & No \\
\hline Outside swab & No & No \\
\hline Inside swab & No & \\
\hline Sample & No & \\
\hline
\end{tabular}

Note. CT, cycle threshold.

SARS-COV-2 was not detected on the masks of HCWs delivering routine care (ie, no AGPs performed) to COVID-19-positive patients (Table 1). SARS-COV-2 was not detected from any samples taken after decontamination using UVGI (Table 1).

No contamination of face masks worn by HCWs during care for known COVID-19 patients (whether worn during intubation or for routine patient care on a ward) was detected. Full face visors were worn by all staff members, which may have blocked contamination of the underlying mask.

Previous studies have investigated contamination of PPE with SARS-COV-2. No contamination was found on N95 masks, goggles, or shoes of exposed HCWs. ${ }^{1}$ Notably, no AGPs were performed in this study. In a study published in Singapore, extensive environmental contamination with SARS-COV-2 was detected in the healthcare setting, but only 1 sample of 10 taken from PPE was positive (the front of $1 \mathrm{HCW}$ 's shoe). ${ }^{3}$

Another study in which masks were artificially contaminated with a high-concentration SARS-CoV-2 solution has brought the effectiveness of UVGI in decontamination into question. ${ }^{4}$ The authors state that it is "hard to imagine a scenario where HCWs would face this degree of mask inoculum" and that their data may inadvertently underestimate decontamination efficacy. ${ }^{4}$ Our study supports this assertion because contamination was not demonstrated during routine care and intubation.
Our study was limited by the small number of masks sampled and the relatively high CT values of the intubated patients (ie, 32 and 36). AGPs in patients with lower CT values and hence higher viral loads may result in greater contamination.

Despite FFP3 masks being marketed as single use, reuse has been suggested by external bodies as a contingency capacity strategy in a crisis situation. Despite the small sample size, it is reassuring that SARS-COV-2 was not detected on any masks worn by HCWs and that no virus was detected after decontamination with UVGI. Importantly, filtration and fit were not retested, and decontamination methods (including UVGI) may affect mask integrity. More evidence is required prior to routine adoption of any such process.

In summary, we have demonstrated that, when worn behind full-face visors, contamination of masks is uncommon during intubation and during extended periods of routine care of COVID-19positive patients. Limited contamination of exposed face masks was documented during intubation, an aerosol-generating procedure. No virus was detectable after a 40-second UVGI decontamination process.

Acknowledgments. None.

Financial support. Financial support for this study was provided by Public Health Wales.

Conflicts of interest. All authors report no conflicts of interest relevant to this article.

\section{References}

1. Ong S, Tan Y, Sutjipto S, et al. Absence of contamination of personal protective equipment (PPE) by severe acute respiratory syndrome coronavirus 2 (SARS-CoV-2). Infect Control Hosp Epidemiol 2020;41:614-616.

2. Guidance COVID-19 personal protective equipment (PPE). United Kingdom government website. https:/www.gov.uk/government/publications/wuhannovel-coronavirus-infection-prevention-and-control/covid-19-personalprotective-equipment-ppe\#ppe-guidance-by-healthcare-context. Published 2020. Accessed May 4, 2020.

3. Ong SWX, Tan YK, Chia PY, et al. Air, surface environmental, and personal protective equipment contamination by severe acute respiratory syndrome coronavirus 2 (SARS-CoV-2) from a symptomatic patient. JAMA 2020; 323:1610-1612.

4. Smith JS, Hanseler H, Welle J, et al. Effect of various decontamination procedures on disposable N95 mask integrity and SARS-CoV-2 infectivity. medRxiv 2020. doi: 10.1101/2020.04.11.20062331.

\title{
COVID-19: Defining an invisible enemy within healthcare and the community
}

\author{
Saif A. Musa MD, FRCP ${ }^{1}$ (1) , Anand Sivaramakrishnan FRCPath ${ }^{2}$, Stephanie Paget FRCPath ${ }^{2}$ and \\ Husam El-Mugamar FRCPath ${ }^{2}$ \\ ${ }^{1}$ Department of Gastroenterology, Chase Farm Hospital, Royal Free London NHS Foundation Trust, Enfield, Middlesex, England and ${ }^{2}$ Department of Microbiology, \\ Barnet Hospital, Royal Free London NHS Foundation Trust, Barnet, England
}

Author for correspondence: Saif Musa, E-mail: saif.musa@nhs.net

Cite this article: Musa SA, et al. (2021). COVID-19: Defining an invisible enemy within healthcare and the community. Infection Control \& Hospital Epidemiology, 42: 495-497, https://doi.org/10.1017/ice.2020.283
To the Editor-The rapid dissemination of severe respiratory coronavirus virus 2 (SARS-CoV-2) throughout the globe has been declared a pandemic. A lack of national and internationally agreed case definitions for healthcare-associated coronavirus disease 2019 


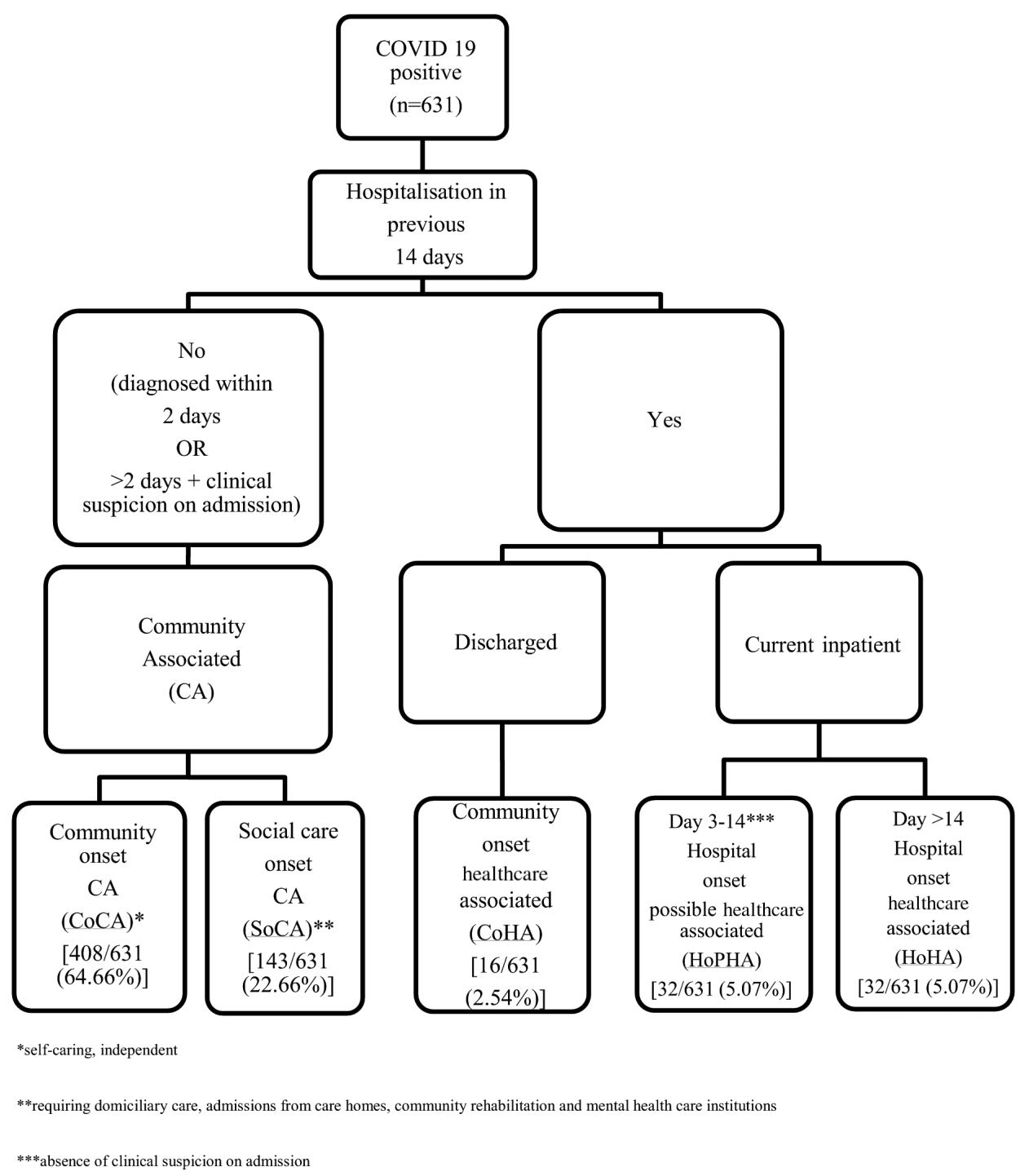

Fig. 1. Algorithm describing COVID 19 cases presenting at our institution from March 1, 2020, to April 15, 2020.

(COVID-19) has led to inconsistencies in describing epidemiology, which limit comparisons. ${ }^{1,2}$ A median incubation period of 5 (range, 1-14) days has been accepted in COVID-19 guidance. $^{3}$ Adapting established case definitions from other infectious diseases, such as Clostridium difficile infection (CDI), may help overcome variability. ${ }^{4}$ All cases with a positive nasopharyngeal real-time polymerase chain reaction (PCR) assay would therefore be described as either healthcare associated (HA) or community associated (CA).

Hospital-onset healthcare-associated (HoHA) COVID-19 would define current hospitalized inpatients residing $>14$ days. Hospital-onset possible healthcare-associated (HoPHA) cases, in those residing between 3 and 14 days in the hospital, in the absence of suspected COVID-19 on admission. New cases diagnosed within 14 days of acute-care hospital discharge would be community-onset, healthcare-associated (CoHA) infection. Community-associated (CA) cases would refer to those diagnosed within 2 days or suspected on admission (diagnosed $>2$ days after admission) and no acute-care hospitalization within the previous 14 days. This group can be further subdivided into those who are independent and self-caring from their own home (CoCA) or those requiring social care, that is, social-onset community-associated (SoCA). Social care includes those requiring domiciliary care (including visiting home care, extra care housing and live in homecare), admissions from care homes, community rehabilitation, and mental healthcare institutions.

We retrospectively applied these definitions to 631 adult COVID-19-positive patients (aged $>16$ years) at our acute-care institution in North London from March 1, 2020, to April 15, 2020 inclusive. The study was registered with our local clinical governance committee. Because all care was routine, in keeping with UK national guidance, ethical approval was not required. In total, HoHA, HoPHA, and CoHA cases accounted for 80 of $631(12.68 \%)$ of all positive cases (Fig. 1). The rates of HoHA and HoPHA COVID-19 cases per total number of hospital admissions during this period were 32 of 1,818 (1.76\%) and 32 of 1,818 (1.76\%), respectively. Median diagnosis occurred 25 days (IQR, 21-43) after admission for HoHA COVID-19 and 9 days (IQR, 6-11) after admission for HoPHA COVID-19, respectively. For CoHA, 16 of 631 patients (2.54\%) presented a median of 8 days (IQR, 2-11) after hospital discharge. Median diagnosis of CA cases occurred 1 day (IQR, 1-2) after testing. 
Recent NHS England guidance recommends screening all emergency hospital admissions on admission followed by a single repeat, for those testing negative, between 5 and 7 days after admission. ${ }^{5}$ Our data demonstrate that healthcare-associated COVID-19 has contributed an important number of cases patients during the height of a pandemic. Sequential screening of non-COVID-19 hospitalized patients beyond this, possibly on a weekly basis up to 14 days after hospital discharge, may prove beneficial in further reducing the threat posed by SARS-CoV-2. Further validation of proposed definitions is required and according to the evolution of CDI definitions, amendments are likely.

Financial support. No financial support was provided relevant to this article.

Conflict of interests. All authors report no conflicts of interest relevant to this article.

\section{References}

1. Praet: Van Praet JT, Claeys B, Coene AS, Floré K, Reynders M. Prevention of nosocomial COVID-19: another challenge of the pandemic.
Infect Control Hosp Epidemiol 2020 [Epub ahead of print]. doi: 10.1017/ ice.2020.166.

2. Vanhems P. Fast nosocomial spread of SARS-CoV2 in a French geriatric unit Lyon Study Group on COVID-19 infection. Infect Control Hosp Epidemiol 2020 [Epub ahead of print]. doi: 10.1017/ice.2020.99.

3. COVID-19: infection prevention and control guidance. Public Health England website. https://assets.publishing.service.gov.uk/government/uploads/ system/uploads/attachment_data/file/886215/COVID-19_Infection_ prevention_and_control_guidance_complete.pdf. Published January 10, 2020. Accessed May 18, 2020.

4. Clostridium difficile infection objectives for NHS organisations in 2019/20 and guidance on the intention to review financial sanctions and sampling rates from 2020/21 improvement. National Health Service England and National Health Improvement website. https://improvement.nhs.uk/ documents/808/CDI_objectives_for_NHS_organisations_in_2019_12 March.pdf. Published February 2019. Accessed May 18, 2020.

5. Operating framework for urgent and planned services in hospital settings during COVID-19. National Health Service England and National Health Improvement website. https:/www.england.nhs.uk/coronavirus/wp-content/ uploads/sites/52/2020/05/Operating-framework-for-urgent-and-plannedservices-within-hospitals.pdf. Published May 14, 2020. Accessed May 18, 2020.

\section{Lack of transparency during the COVID-19 pandemic: Nurturing a future and more devastating crisis}

\author{
Alain Braillon PhD MD ${ }^{1}$ (1) \\ ${ }^{1}$ Retired
}

"Collaboration is a key part of the success of any organization, executed through a clearly defined vision and mission and based on transparency and constant communication." Dinesh Paliwal. (https://en.wikipedia.org/ wiki/Dinesh_Paliwal)

To the Editor-The editor must be commended for having provided to Rahimi et $\mathrm{al}^{1}$ the opportunity to pledge transparency during the COVID-19 crisis, a major issue that has been overlooked in scholarly journals. This issue has two aspects, most concrete.

First, healthcare professionals have faced bullying when speaking out in the media about their real-life experiences of the COVID-19 crisis as they faced basic resources shortage or bureaucratic barriers precluding adequate care or even protecting themselves. In The New York Times, Scheiber and Rosenthal reported that nurses and doctors were bullied for speaking out. ${ }^{2}$ Similarly, in the United Kingdom, hospital professionals were gagged for voicing concerns about shortages of equipment to protect against coronavirus. ${ }^{3}$ This occurrence is most frightening because in the United Kingdom the culture of transparency is an old one and has even been strengthened by a comprehensive framework of legal protections: the Employment Rights Act 1996, amended as Public Interest Disclosure Act 1998, and the Defamation Act of 2013. In other European countries, no

Author for correspondence: Alain Braillon, E-mail: braillon.alain@gmail.com

Cite this article: Braillon A. (2021). Lack of transparency during the COVID-19 pandemic: Nurturing a future and more devastating crisis. Infection Control \& Hospital Epidemiology, 42: 497-498, https://doi.org/10.1017/ice.2020.271 protections exist for whistleblowers, and the motto seems to be "Silence is golden"!

This issue also extends to scientific committees advising governments. In Great Britain, the government deliberately kept secret the list of participants in its committee of scientific experts. ${ }^{4}$ In France, the Haut Conseil de la Santé Publique (High Council of Public Health), the expert body of the Ministry of Health for the French government, issued 4 dozen reports about COVID-19. As a member, when recruited, I had to sign a form swearing I would respect the "duty of reserve" regarding the content of meetings. This issue is not a theoretical one: I was forced to resign (October 3, 2018) from Public Health France's scientific committee after a written threat of being sued for such a breach if I refused to resign because whistleblowing by a civil servant is a specific criminal offense in France (Law 83-634, Article 26). This situation contrasts with that the United States where the Lloyd-La Follette Act of 1912 protects civil servants who criticize superiors from official retribution.

In 1998, Söderlund summarized the challenges faced by healthcare systems "protecting against catastrophic illness events," "improving allocative efficiency and equity of access to services," and "combating cost escalation," among many key issues." Setting transparent and fair rules is a mandatory prerequisite for confidence and effectiveness. Old democracies are deliberately breaching their most basic principle. The crisis is before us.

Acknowledgments.

Financial support. No financial support was provided relevant to this article. 